\title{
Thermo-physical performances of living walls via field measurements and numerical analysis
}

\author{
U. Mazzali ${ }^{1}$, F. Peron $^{1} \&$ M. Scarpa ${ }^{2}$ \\ ${ }^{1}$ Unità di Ricerca Innovazione e Costruzione Efficiente, \\ Università IUAV di Venezia, Venezia, Italy \\ ${ }^{2}$ Dipartimento di Fisica Tecnica, Università degli studi di Padova, \\ Padova, Italy
}

\begin{abstract}
In the urban area the air temperature has been growing at a faster rate (Urban Heat Island UHI) leading to greater use of air-conditioning and energy demand. One possible strategy to lower ambient temperature is to increase the amount of greenery in the city. In this context we have assisted recently in a rediscovering of buildings envelopes claddings by green walls, living walls and green roofs. Green walls may consist of green façades made up of traditional creepers and living walls are vertical claddings with plants, installed on the building façade. A very detailed field measurement campaign was performed on a living wall with the aim of evaluating its performance versus a traditional envelope. The field measurements were performed between June and September 2011. Hourly measurements of surface temperatures, heat fluxes, ambient and internal temperatures, ambient and internal relative humidity, air velocity in the living wall cavity and climatic variables have been collected for the bare and covered wall. Using a numerical model, validated via field measurements, a multiparametric analysis has been performed considering the effect on energy consumption and temperature behaviour for different orientations of the living wall in different locations.
\end{abstract}

Keywords: building façade, living wall, energy simulations, field measurements.

\section{Introduction}

In recent years green claddings over buildings have seen a significant increase in their application. A study including their behavior and their influence on cooling 
energy consumption buildings was required. The aim of this work is to assess the influence of a living wall on cooling energy consumption of standard office with three differently oriented external walls, over which the green wall is applied. Moreover the dependence on latitude was investigated by simulating the office in three latitudes of the Mediterranean climate. First of all, in order to assess the living wall thermal behavior, a filed measurement of an existing living wall was performed. Then a mathematical model, validated via field measurements, was implemented. Finally a finite volume numerical model of the office room was created, in order to quantify more precisely the effective influence on cooling energy consumptions. The impact that the living wall can have over the back wall is in dependence on multiple variables. First of all the protection effect from the external solar radiation that is one of the most important thermal loads to control during the summer period in order to reduce cooling energy consumption. This variable is directly related with the wall orientation. Then, the impact of the living wall is also in dependence on the kind of wall over which is installed, i.e. the back wall could be an insulated wall or a massive wall. Other parameters, directly related with the plants are evapotranspiration rate, Leaf Area Index, (Palomo Del Barrio [1]) solar absorption coefficient and emissivity (Rubio et al. [2]) of the vegetation. Some studies were performed on thermal effects of green claddings (Kontoloeon and Eumorfopoulou [3]) showing how one of the most important effects of the green wall is the external surface temperature reduction from a minimum of $1{ }^{\circ} \mathrm{C}-2^{\circ} \mathrm{C}$ on the North surface to a maximum of $16^{\circ} \mathrm{C}-17^{\circ} \mathrm{C}$ on the West surface, with a direct influence on summer cooling energy consumption of a standard room. The reduction assessed was of around $4.65 \%$ for a North oriented wall and $20.08 \%$ for a West oriented wall at Greek latitudes.

\section{Methods}

It was possible to perform a field measurement of a living wall installed in Northern Italy. In the following sections the field measurements of the green architectural cladding and the mathematical model validation will be shortly described. Then the finite volume mathematical model of the office room will be outlined.

\subsection{Field measurements and mathematical model}

The measurement campaign was performed on a living wall, South-West oriented, in a nursery garden in Lonigo, located in the North-East of Italy, as visible in Figure 1. The main feature is the presence of a triple felt in which the first layer let the water flow between the PVC panel and the felt itself, the second layer allows the roots to propagate and the third felt has a mechanical function, as a support during plant rooting. The measurement campaign was performed in summer 2011, in particular between June and September 2011. 


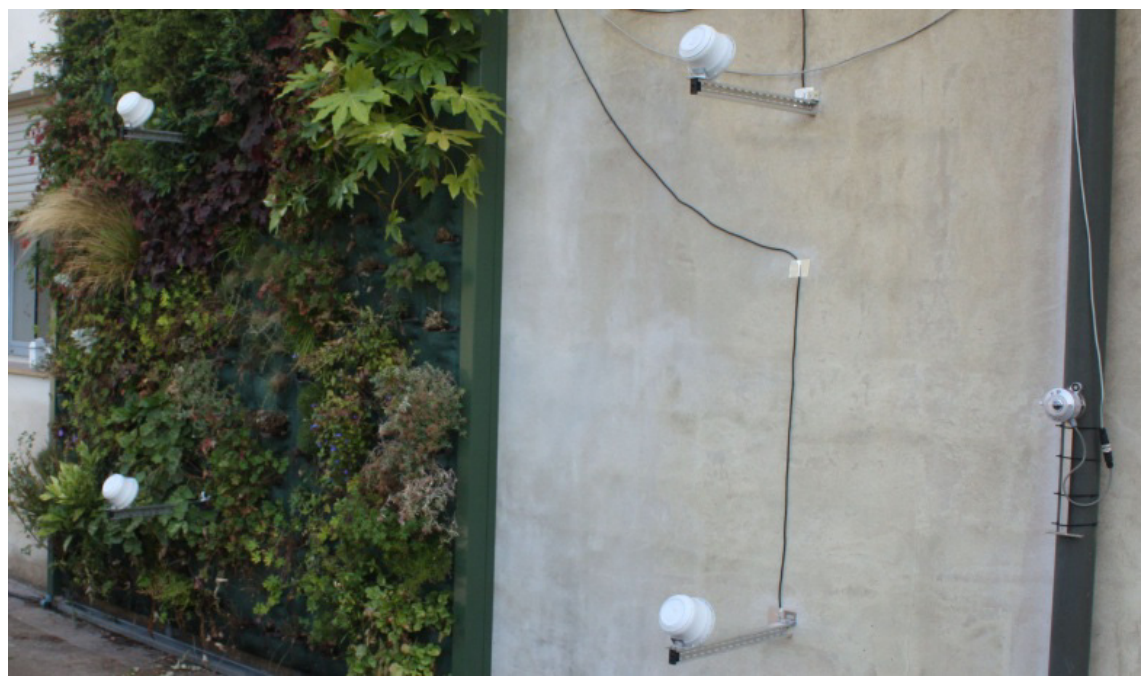

Figure 1: $\quad$ Living wall monitored in Lonigo, Italy.

The numerical model of the living wall used in this project is based on the finite volume approach. In a few words, the building structure is described via a $\mathrm{RC}$ network integrating the air gap as well. The model structure is visible in Figure 2.

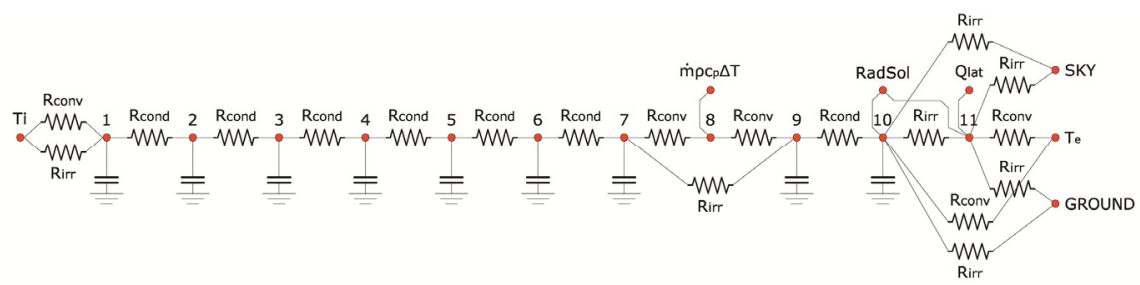

Figure 2: $\quad$ Thermal nodes of the mathematical model.

\subsection{Standard office room model for cooling reduction assessment}

In this work a further finite volume model was developed in order to simulate the thermal behavior of the room used as office. The room has an area of $25 \mathrm{~m}^{2}$ and it has three walls facing the outside. The fourth wall and the two slabs, the upper and the lower one, are considered adiabatic. It was assumed that the internal loads inside the office were $6 \mathrm{~W} / \mathrm{m}^{2}$ as the actual Italian regulation UNI/TS 11300:2008 [4], prescribes. The ventilation rate is $11 \mathrm{l} /(\mathrm{s}$ person) as UNI 10339:1995 [5] prescribes for offices. Each wall has a win-to-wall ratio, i.e. opaque wall to transparent wall ratio, of $15 \%$. This value was considered consistent with the actual Italian regulation on minimum windows area for ventilation and illumination requirements. 


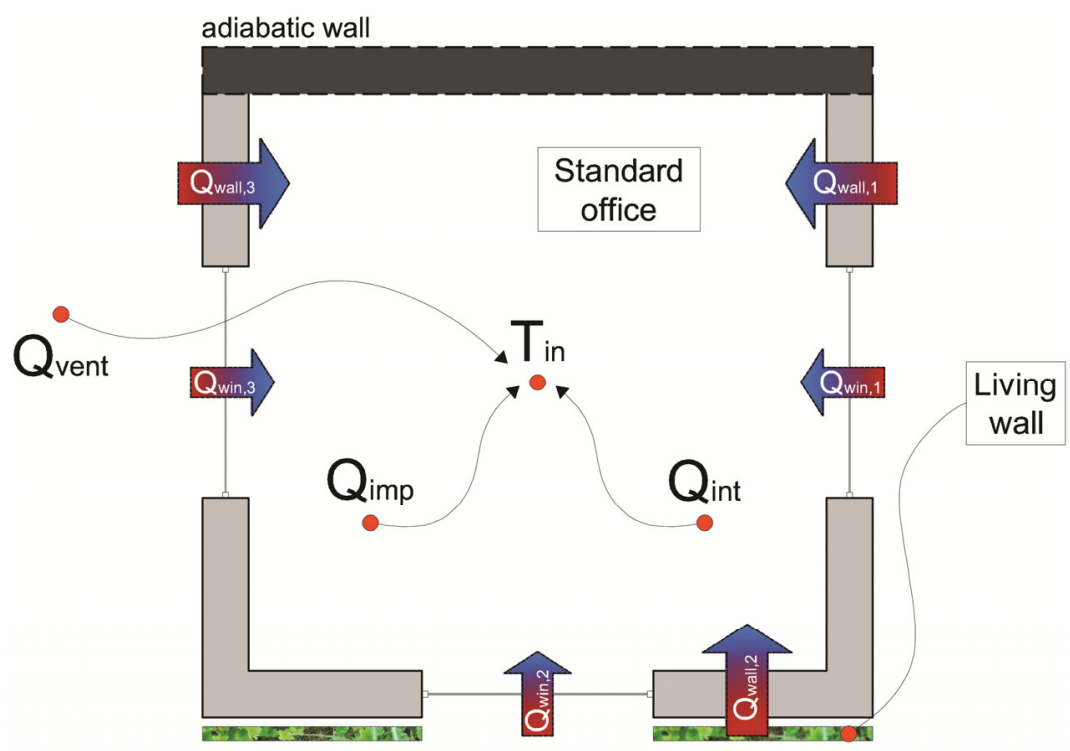

Figure 3: Scheme of the finite volume standard zone model with an example of South living wall installation.

The thermal balance, as shown in figure 3, was developed for the internal temperature node $\left(\mathrm{T}_{\text {in }}\right)$ considering energy contributions coming from walls $\left(\mathrm{Q}_{\text {wall, } \mathrm{n}}\right)$, windows $\left(\mathrm{Q}_{\text {win, }}\right)$, internal loads $\left(\mathrm{Q}_{\text {int }}\right)$, natural ventilation $\left(\mathrm{Q}_{\text {vent }}\right)$ and from the cooling plant $\left(\mathrm{Q}_{\mathrm{imp}}\right)$. The latter contribution was implemented with the aim to ensure a constant internal temperature setpoint of $26^{\circ} \mathrm{C}$. The most important equations of the thermal balance, to evaluate energy contributions, are the following:

$$
\begin{gathered}
Q_{\text {wall }, n}=A_{n} h_{i}\left(T_{\text {sup }, n}-T_{\text {in }}\right) \\
Q_{\text {win }, n}=A_{n} \operatorname{solrad}_{n} \tau_{e, n}+A_{n} U_{\text {win }, n}\left(T_{\text {ext }}-T_{\text {in }}\right) \\
Q_{\text {vent }}=\frac{\rho_{\text {air }} c_{p, \text { air } V n}}{3600}\left(T_{\text {ext }}-T_{\text {in }}\right)
\end{gathered}
$$

where $A$ is the wall area, $h_{i}$ is the internal convection and radiation coefficient equal to $7,7 \mathrm{~W} / \mathrm{m}^{2} \mathrm{~K}$ as indicated in the UNI EN ISO 6946:2008 [6], $T_{\text {sup }, n}$ is the internal surface temperature calculated with the numerical model in (Mazzali et al. [7]), $T_{\text {in }}$ internal ambient temperature, sol $_{\text {rad }}$ is the solar radiation impinging on the $\mathrm{n}$-th window, $\tau_{e}$ is the energy transmission coefficient for the $\mathrm{n}$-th window pane, $U_{w i n, n}$ is the transmittance of the n-th window, $T_{e x t}$ is the external air temperature, $\rho_{\text {air }}$ is the air density, $c_{p, a i r}$ is the air specific heat, $V$ is the room volume and $n$ is the ach value for the considered room. 


\section{Results}

\subsection{Monitoring campaign results and model validation}

The dependence of surface temperatures on solar radiation is visible in figure 4; the temperature difference between external surface temperature of the bare wall and the one behind the living wall cladding, ranges from $12^{\circ} \mathrm{C}$ to $20^{\circ} \mathrm{C}$ during sunny days and it is around of $5^{\circ} \mathrm{C}$ during cloudy days. Other important results are heat flux reduction in the order of $70 \%-80 \%$ and air velocity, in the cavity between the green cladding and the wall, from $0.2 \mathrm{~m} / \mathrm{s}$ to $0.5 \mathrm{~m} / \mathrm{s}$ (Mazzali et al. [7]).

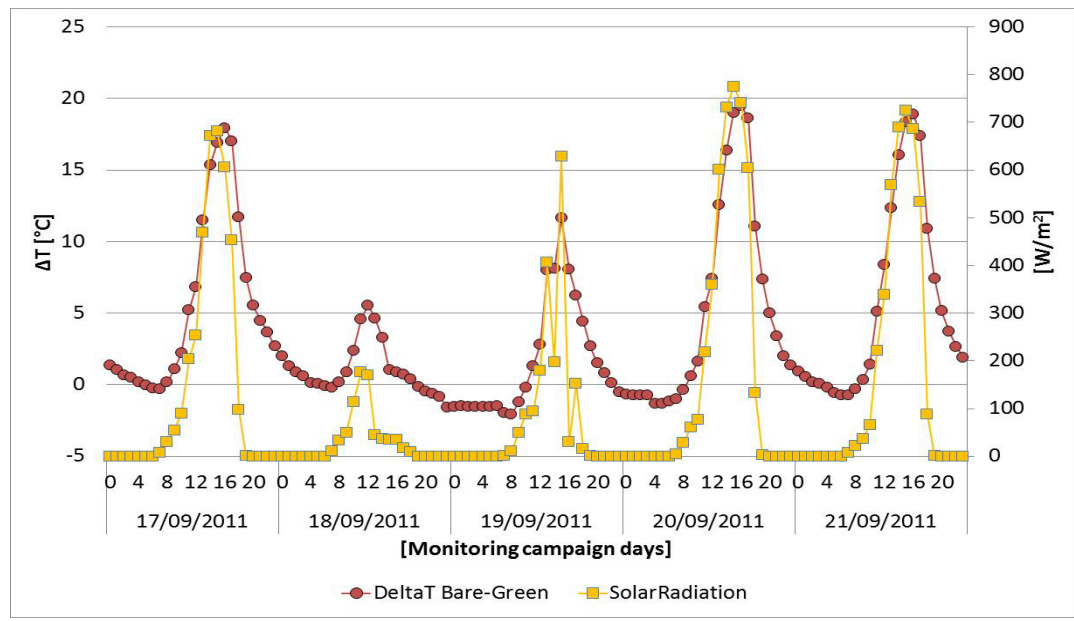

Figure 4: Temperature difference vs. solar radiation.

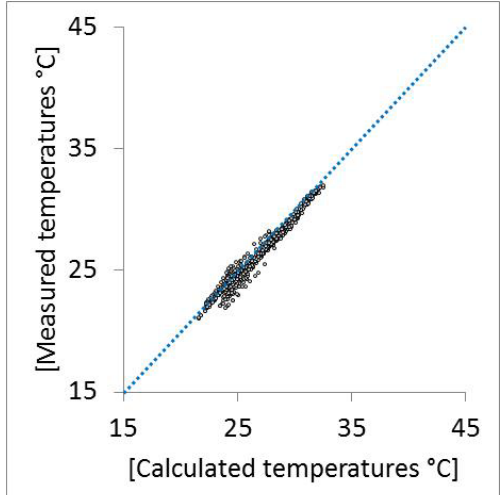

a)

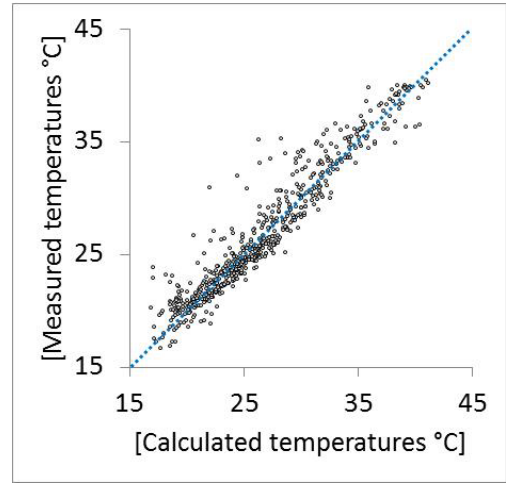

b)

Figure 5: Correlation between calculated values and measured values: a) external surface temperatures; b) plant temperatures. 
The mathematical model compared with field measurements as regards external surface temperatures and heat fluxes shows a good correspondence of the external surface temperatures and plant temperatures as shown in figure 5 .

\subsection{Cooling energy reduction assessment in standard conditions}

A nomograph was created to better understand the dependence of the cooling energy reduction on the living wall orientation, on the kind of wall behind the green cladding and on the latitude. Three kinds of office test room external wall were assumed:

- massive wall with $40 \mathrm{~cm}$ of concrete (MW)

- internal insulated wall with $15 \mathrm{~cm}$ of polystyrene with $30 \mathrm{~cm}$ of concrete (IIW)

- external insulated wall with $30 \mathrm{~cm}$ of concrete with $15 \mathrm{~cm}$ of polystyrene (EIW).

The influence of the living wall over cooling energy consumption was investigated considering the 4 main orientations North, East, South and West and three Italian latitudes: Northern ones corresponding to Verona $\left(45^{\circ} 22^{\prime} \mathrm{N}, 10^{\circ}\right.$ $\left.52^{\prime} \mathrm{E}\right)$, central ones corresponding to Rome $\left(41^{\circ} 38^{\prime} \mathrm{N}, 12^{\circ} 36^{\prime} \mathrm{E}\right)$ and southern ones corresponding to Trapani $\left(37^{\circ} 55^{\prime} \mathrm{N}, 12^{\circ} 30^{\prime} \mathrm{E}\right)$. In figure 6 the improvement percentages in dependence on orientation and latitude were reported. The case where the wall is externally insulated turns out to be the one in which the benefits of a juxtaposition of living wall are minimized. The values ranges, in fact, between $1.4 \%$ and $2.6 \%$ compared to a case without the installation of the plant wall. The second case is represented by an internal

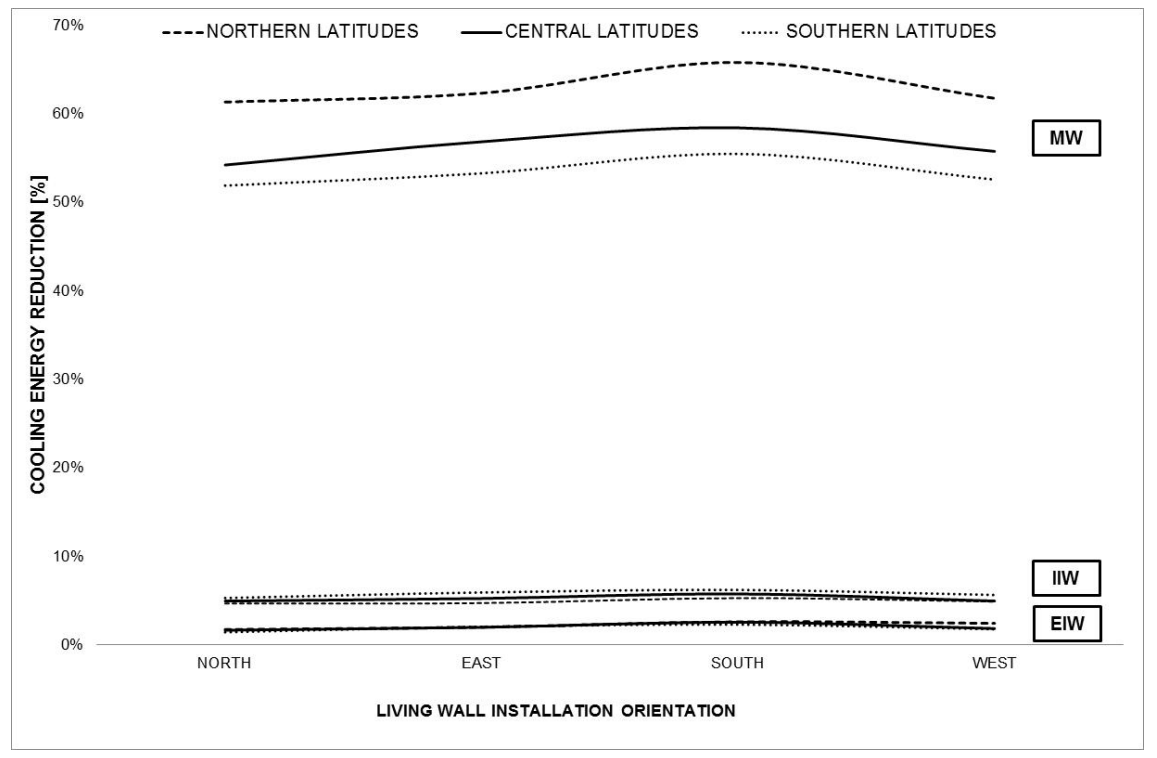

Figure 6: Cooling energy reduction percentage for different latitudes and walls. 
insulated wall. In this case the presence of a green coating leads to a reduction in cooling energy consumptions that ranges from $4.7 \%$ and $6.2 \%$. Greater benefits are obtained at lower latitudes and by installing the green wall on a south exposed wall. In this case a reduction of $5.3 \%$ for a latitude corresponding to Northern Italy and a reduction of $6.2 \%$ for a latitude corresponding to Southern Italy are obtained. Finally the graph points out the benefits of a living wall application over non insulated walls with good inertia. For this kind of walls cooling energy reduction up to $65.8 \%$ can be obtained. Moreover, regardless of the latitude and the wall type the best effects are obtained by the living wall installation on a South external wall. The results in term of absolute values are shown in Figure 7. In particular it is possible to note that lower latitudes correspond to highest cooling energy consumption with or without the presence of the green wall.

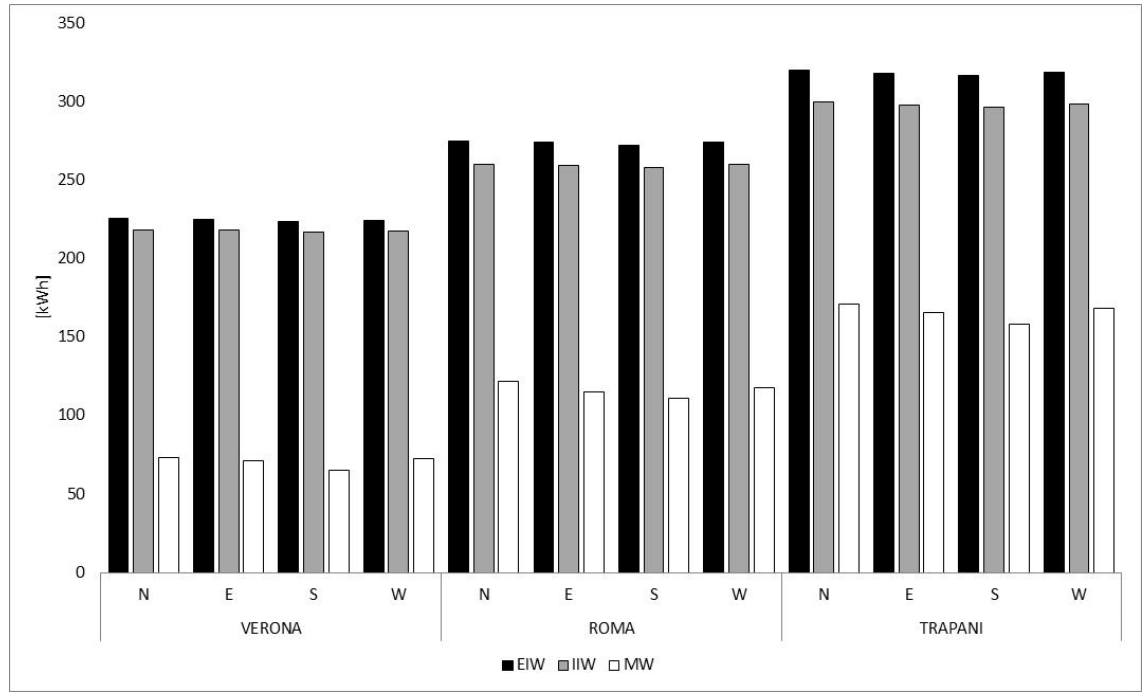

Figure 7: Cooling energy reduction for different latitudes and kind of walls.

\section{Discussion}

The benefit obtained on energy cooling consumption is clearly related to the type of wall on which the green wall is installed, and to the orientation of the wall. The presence of an insulation layer within the stratigraphy of the wall severely reduces the effectiveness of the plant cladding reducing the incoming heat fluxes. Even if the difference is small, the effect of positioning the insulation layer on the external side of the wall, in the classic configuration, further reduces the effect of the plant protection by limiting immediately the incoming energy. This behavior is less evident if the insulation layer is installed on the internal side of the wall, since the mean wall temperature is higher than the previous case and the wall is able to storage more thermal energy. The positive effect of the living 
wall installation is evident in the case of massive wall. In this case, as a matter of fact, the wall itself is the only thermal resistance that reduces the energy income from the outside, because no insulation layer is present. The incident solar radiation represents a high thermal load that the wall has to break down and the presence of a shielding plant together with the effect of evapotranspiration given by the vegetation, is able to reduce the energy need for cooling in a significant way.

Further considerations can be made on the orientation of the wall. At all latitudes the best benefit is achieved by installing the cladding on a South wall. This is directly linked to the high radiation impinging on such areas during the summer. In any case, in general terms, also East and West orientation offers interesting improvements. Less evident are the effects of the installation on a North surface for obvious reasons related to the lower contribution of solar radiation.

\section{Conclusions}

The present work studied the thermal effect of a living wall installed on different types of external walls at different latitudes of the Mediterranean climate. Starting with a detailed field measurements and developing a mathematical model, it was possible to estimate the effect of the cladding on the internal environment behind the green wall. Interesting considerations came out about the reduction of cooling energy consumption of a typical office exposed on three sides and with a win-to-wall ratio of $15 \%$. The best results can be obtained with a massive south-facing wall where the reduction of the cooling energy reaches values of about $66 \%$ for latitudes corresponding to those of Northern Italy. Lower benefits were found on walls with an insulation layer. In these cases the reduction is around $2 \%$ in the case of externally insulated walls and around $5 \%$ in the case of internally insulated walls. The most effective orientation of the cladding, regardless the type of wall and the latitude, was found to be South.

\section{Acknowledgement}

Thanks to Sundar Italia for the green wall cladding facility test.

\section{References}

[1] Palomo Del Barrio, E, Analysis of the green roofs cooling potential in buildings, Energy and buildings, 27, 179-193, 1998.

[2] Rubio, E., Caselles, V., Badenas, C., Emissivity measurements of several soils and vegetation types in the $8-14 \mu \mathrm{m}$ wave band: analysis of two field methods, Remote sensor environment, 59, 490-521, 1997.

[3] Kontoleon, K., Eumorfopoulou, E., The effect of the orientation and proportion of a plant-covered wall layer on the thermal performance of a building zone, Building and environment, 45, 1287-1303, 2010. 
[4] Uni, UNI/TS 11300:2008 - Parte 1, Determinazione del fabbisogno di energia termica dell'edificio per la climatizzazione estiva ed invernale, 2008.

[5] Uni, UNI 10339:1995, Impianti aeraulici a fini di benessere - Generalità classificazione e requisiti, 1995.

[6] Uni, UNI 6946:2008, Resistenza termica e trasmittanza termica - Metodo di calcolo, 1995.

[7] Mazzali, U., Peron, F., Scarpa, M., Development and Validation of a Numerical Model for Living Walls via Field Measurements and Evaluation of Thermal Performance on a Building Wall, Proceedings of Cobee Conference 2012, in press, 2012. 